\title{
Dissection of placebo analgesia in mice: the conditions for activation of opioid and non-opioid systems
}

\author{
Journal of Psychopharmacology \\ 24(10) (2010) 1561-1567 \\ (c) The Author(s), 2010 \\ Reprints and permissions: \\ http://www.sagepub.co.uk/ \\ journalsPermissions.nav \\ ISSN 0269-8811 \\ $10.1177 / 0269881109104848$
}

\author{
J-Y Guo Key Laboratory of Mental Health, Institute of Psychology, Chinese Academy of Sciences, Beijing, P.R. China. \\ J-Y Wang Key Laboratory of Mental Health, Institute of Psychology, Chinese Academy of Sciences, Beijing, P.R. China. \\ F Luo Key Laboratory of Mental Health, Institute of Psychology, Chinese Academy of Sciences, Beijing, P.R. China.
}

\begin{abstract}
Amanzio and Benedetti (J Neurosci 1999; 19: 484-494) first addressed the conditions necessary for the activation of opioid and non-opioid placebo responses in human. Here, we investigated whether placebo analgesia is subdivided into opioid and non-opioid components in mice by using the model of hot-plate test. Drug conditioning was performed by the combination of the conditioned cue stimulus with the unconditioned drug stimulus, either opioid agonist morphine hydrochloride or non-opioid aspirin. Placebo analgesic responses were evoked by an exposure to a conditioned cue previously paired with drug conditioning. Morphine conditioning produced placebo responses that were completely antagonised by naloxone. By contrast, the conditioned cue after aspirin conditioning elicited a placebo effect that was not blocked by naloxone.
\end{abstract}

Therefore, we first evoked opioid and non-opioid placebo responses in mice that were either naloxone-reversible or naloxone-insensitive, depending on the drug used in conditioning procedure. These findings support that the mechanisms underlying placebo analgesia may depend on the drug conditioning that was originally performed. The present procedure of mice may serve as a model for further understanding of the opioid and non-opioid mechanisms underlying placebo responses.

\section{Key words}

cue; endogenous opioids; mice; morphine; nonsteroid anti-inflammatory drugs; placebo analgesia

\section{Introduction}

Placebo effects, the physiological or psychological changes associated with the administration of inert substances or procedures, can both enhance and obscure the effects of therapeutic interventions. Most of the placebo researches have been performed in the field of pain medicine. The neural basis of placebo analgesia was first established by Levine, et al. (1978), who discovered the fact that the placebo response could be blocked by the opioid receptor antagonist naloxone. This indicates the involvement of the endogenous opioid system. Following this finding, complex experimental designs have elucidated several components underlying the placebo analgesic response, and other studies subsequently confirmed this exciting and provocative hypothesis (Hoehn-Saric and Masek, 1981; Grevert, et al., 1983; Levine and Gordon, 1984; Benedetti, 1996).

Fields and Levine (1984) were the first to hypothesize that placebo response may be subdivided into opioid and nonopioid components. In particular, they suggested that different physical, physiological, and environmental situations could affect the endogenous opioid system differently. This concept was further supported by the finding that placebo effect was not always mediated by endogenous opioids (Gracely, et al., 1983). Thus, the the conditions necessary for the activation of opioid systems were to be identified. This problem was addressed by Amanzio and Benedetti (1999), who showed that expectation or a conditioning procedure is capable of activating different types of placebo analgesia.

A likely candidate for the mediation of placebo-induced analgesia is the opioid-related neuronal network in the brain (Fields and Price, 1997). This hypothesis was supported by a recent brain imaging study in which the authors found that the very same brain regions in the cerebral cortex and brainstem could be affected by either a placebo or a rapidly acting opioid agonist remifentail, thus indicating a related mechanism in placebo- and opioid-induced analgesia (Petrovic, et al., 2002). The direct demonstration of placebo-induced release of endogenous opioids were obtained using in vivo receptor binding with positron emission tomography by Wager, et al. (2007) 
and Scott, et al. (2008). Although neurochemical mechanisms have not yet been identified in nonopioid-meditated placebo, the possible involvement of some neurotransmitters has been shown in some condition. For instance, when a placebo was given after repeated administration of the analgesic drug sumatriptan, the levels of growth hormone increased and cortisol secretion decreased (Benedetti, et al., 2003). However, because it is difficult to invasively conduct experiments in human subjects, the biological mechanisms of opioid and non-opioid placebo responses remain largely unknown.

It has been reported that mice or rats, as many other mammals, could display associative learning (Garcia, et al., 1999; Fanselow and Poulos, 2005). Mice or rats could learn to associate the cue condition with placebo effect by special procedures (Herrnstein, 1962; Pihl and Altman, 1971). For example, scopolamine hydrobromide disrupted the learned behavior of rats in a predictable manner. Herrnstein (1962) showed that physiological saline could mimic the effect of the drug to some extent when the two substances were alternately administered in a series of injections. Therefore, on the basis of Amanzio and Benedetti's (1999) experiments and previous animal work on placebo responses, we investigated whether placebo analgesia would also be divided into opioid and non-opioid components in mice using hot-plate test, in an attempt to clarify the mechanism of activation of opioid and non-opioid responses. We hypothesised that cue condition together with morphine or aspirin drug might evoke two different types of placebo responses in mice.

\section{Materials and method}

\section{Animals}

Female ICR mice weighing 18-22 $\mathrm{g}$ at the start of the experiment were used. Animals were housed in groups of four in polycarbonate tubs $(43 \mathrm{~cm} \times 23 \mathrm{~cm} \times 18 \mathrm{~cm})$ with pine sawdust bedding. The housing room was kept in a 12:12 h day-night cycle (lights on at 07:00 a.m.) and at an ambient temperature of $20-22{ }^{\circ} \mathrm{C}$. Food and water were available ad libitum. Animals were handled for at least 2-3 days before the start of the experiments. All experiments followed the Guidelines on Ethical Standards for Investigation of Experimental Pain in Animals (Zimmermann, 1983) and were approved by the Institutional Animal Care and Use Committee of the Institute of Psychology of the Chinese Academy of Sciences.

\section{Drug}

All drugs were administered via intraperitoneal (i.p.) injection. Naloxone (Sigma, USA) was administered at a dose of $5 \mathrm{mg} / \mathrm{kg}$ in sterile solution of $\mathrm{NaCl} 0.9 \%$. The opioid agonist morphine hydrochloride and the opioid antagonist naloxone products were from Sigma, St. Louis, Missouri, USA. Morphine was administered at a dose of $10 \mathrm{mg} / \mathrm{kg}$ in sterile solution of
$\mathrm{NaCl}$ 0.9\%. Aspirin (Bayer, Germany), a nonsteroid antiinflammatory drug (NSAID) with no activity on opioid receptors, was administered at a dose of $400 \mathrm{mg} / \mathrm{kg}$ in sterile solution of $\mathrm{NaCl} 0.9 \%$. Drugs were injected in a volume of $0.1 \mathrm{ml} / 20 \mathrm{~g}$ (i.p.).

\section{Apparatus}

The place compartments $(30.5 \mathrm{~cm} \times 24.1 \mathrm{~cm} \times 21 \mathrm{~cm})$ were purchased from Med Associates, Inc. These units include a grid floor and a blue light different from the home cage, which act as the conditioned stimulus. The hot-plate test employed a commercially available apparatus consisting of acrylic resin cage (diameter: $20 \mathrm{~cm}$; height: $31 \mathrm{~cm}$ ) and a thermo-controlled aluminum plate (Model RB-200, Chengdu TME Technology Co., China).

\section{Hot-plate test}

The hot-plate test was used to measure response latencies according to the method described by Chan and Yeung (2006). Animal was placed on the hot plate maintained at $55 \pm 0.5^{\circ} \mathrm{C}$. The surface temperature was continuously monitored with a digital thermometer. The time between placement of the animal on the hot plate and the occurrence of either licking the hind paws, or shaking, or jumping off from the surface was recorded as the response latency. This latency was recorded $30 \mathrm{~min}$ after the administration of vehicle or drug. A cut-off time of $60 \mathrm{~s}$ was established to prevent tissue damage. The reason for using the hot-plate test was that some supraspinal mechanism was considered involved in this pain model (Le Bars, et al., 2001). By contrast, other nociceptive tests such as the tail-flick test are spinal reflexes, as it persists after section or cold block of upper parts of the spinal cord (Irwin, et al., 1951; Bonnycastle, et al., 1953; Sinclair, et al., 1988).

\section{Procedure}

Animals were randomly divided into seven groups, and the complete experimental procedure is shown in Figure 1. All drugs were administered $30 \mathrm{~min}$ before the hot-plate test and were given once every $12 \mathrm{~h}$. The hot-plate test was performed with saline (groups 4-7) or without any treatment (groups 1-3) in the first session in all groups, which was used as a baseline. Group 1 (natural history) was tested with the hot plate for five consecutive days at 8:30 a.m. and 8:30 p.m. without receiving any treatment. To investigate whether the saline injection affected experimental results, mice in group 2 were tested with the hot plate on days 1 and 3 without any treatment, but each received an injection of saline on days 2 and 4, and the paw lifting latency was measured 30 min later. To ascertain whether naloxone could affect the hot-plate test, mice in group 3 received similar treatment procedure as group 2, but naloxone ( $\mathrm{NaCl} 0.9 \%$ solution) was given instead of saline. Group 4 mice were treated with saline on day 1 at 8:00 a.m. and day 2 at 


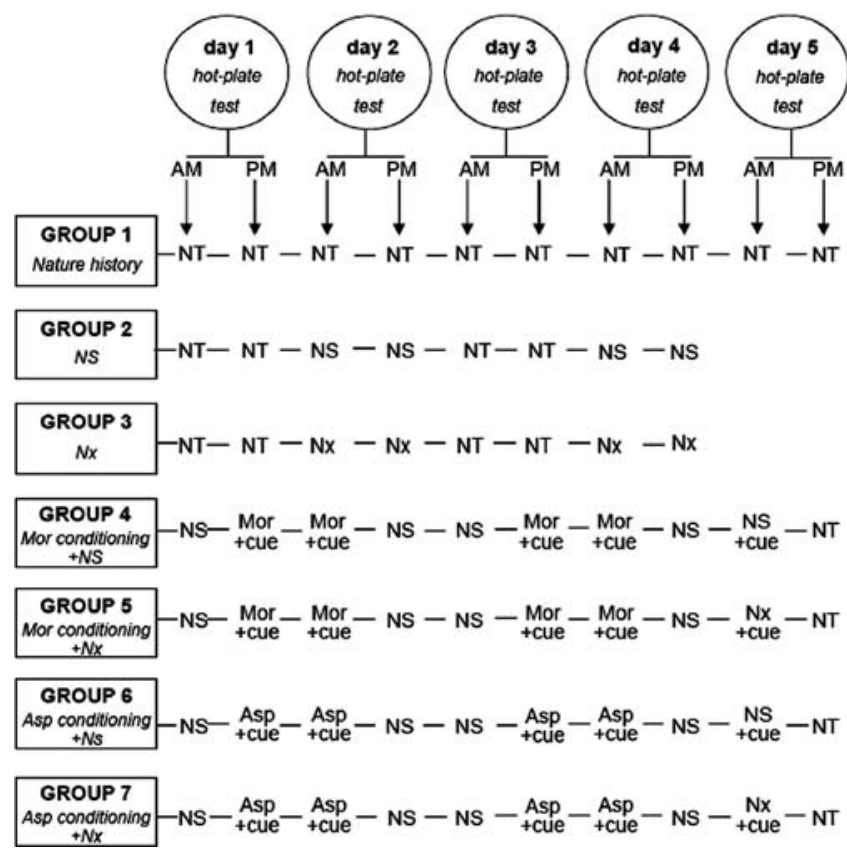

Figure 1 Experimental paradigm used in the study to identify the opioid and nonopioid components of placebo analgesia in mice. Below each group the experimental condition is specified. NT, no treatments; NS, saline; Nx, naloxone; Asp, aspirin; Mor, morphine.

8:00 p.m., but with morphine on day 1 at 8:00 p.m. and day 2 at 8:00 a.m.. They were then put into the cue chambers for $30 \mathrm{~min}$ before receiving the scheduled hot-plate test. The same procedure was repeated on days 3 and 4 . On day 5, the mice were placed in the cue compartments and they were treated with saline at 8:00 a.m. and with morphine for $30 \mathrm{~min}$ before the nociceptive test. Another hot-plate test was run again at 8:30 p.m. as in group 1. The procedure for group 5 was the same as that for group 4, but the rats were treated with naloxone instead of saline on day 5 at 8:00 a.m.. Groups 6 and 7 were treated similarly as groups 4 and 5 , except that morphine was replaced with the non-opioid aspirin on days $1-4$. The number of animals per group was 12 , and those mice scoring less than $5 \mathrm{~s}$ or more than $60 \mathrm{~s}$ in the pretest were rejected (about 20\%). All mice maintained or gained body weight during the experimental period (data not shown).

\section{Data analysis}

All data are expressed as mean \pm SEM. Significance of difference between the two groups was evaluated using Student's $t$-test. One-way analysis of variance (ANOVA) followed by Newman-Keuls' test was used for repeated measurements (in the same animals). A $P$ value less than 0.05 was considered to indicate a statistically significant difference.

\section{Results}

\section{The natural history of hot plate}

The natural history group showed no variation of pain tolerance when the hot-plate test was repeated for five consecutive days at 8:30 a.m. and 8:30 p.m. (ANOVA, $F(9,99)=0.14 ; P=0.998$ ), indicating that the hot plate could produce constant pain tolerances for several days (Figure 2). Thus, when the hot-plate test was performed without any treatment, it is capable of always producing constant and consistent results within 5 days. Therefore, any departure from this pain tolerance baseline (natural history) can be viewed as a placebo analgesic effect.

\section{Effect of naloxone on hot-plate test}

First of all, we tested whether the saline injection itself could affect the experimental results. As shown in Figure 3, injection of saline on days 2 and 4 did not produce any difference in hotplate test when compared with days 1 and 3 (ANOVA, $F(7,77)=0.14 ; P=0.995)$ among days $1-4$. Then, we tested whether naloxone affects this type of experimental pain. Hotplate test outcome was again not affected by naloxone injection on days 2 and 4 when compared with either their measures on days 1 and 3 (ANOVA, $F(7,77)=0.15 ; P=0.994$ ) or with the result of saline group on days 2 and 4 (ANOVA, $F(7,77)=0.12 ; P=0.997)$. Thus, neither naloxone nor saline injection affects the experimental pain.

\section{Effect of conditioned cue with morphine hydrochloride conditioning}

A significant difference was shown in group 4 when the paw latency was measured for five consecutive days (ANOVA,

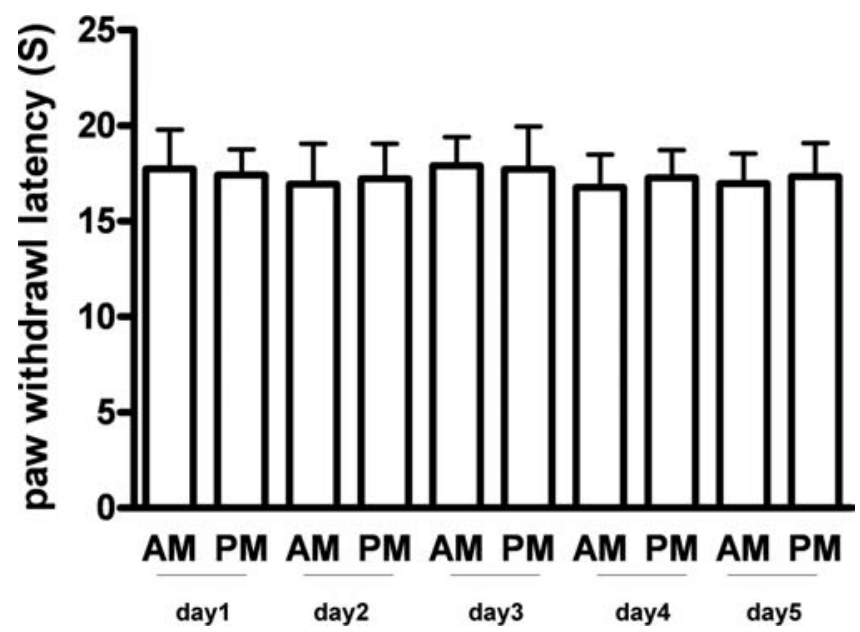

Figure 2 Analysis of the natural history of hot-plate test. Means and SEM of the natural history are shown for group 1 in five consecutive days at 8:30 a.m. and 8:30 p.m.. 


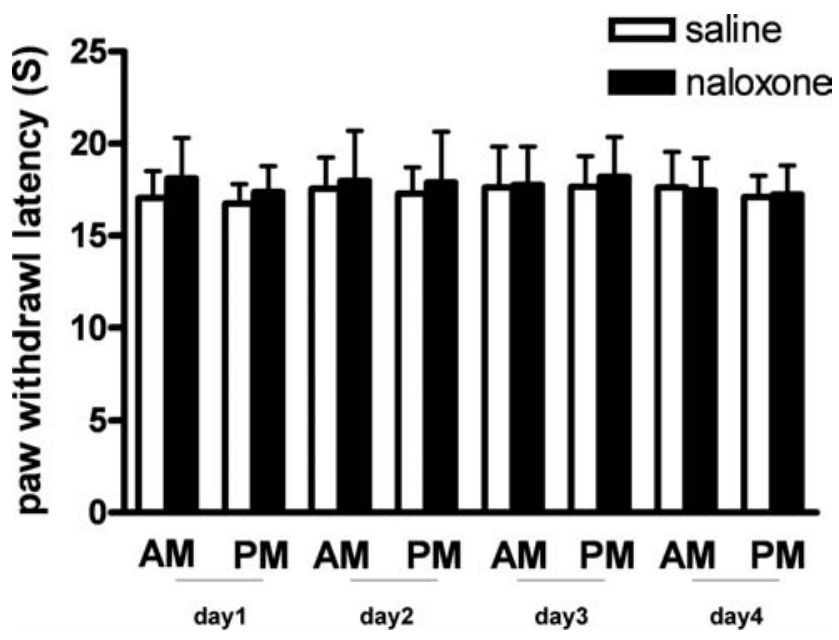

Figure 3 Effect of saline or naloxone injection on daily pain tolerance. Mice in group 2 (the 'saline group', blank bars) were tested with the hot plate on days 1 and 3 without any treatment, but each received an injection of saline on days 2 and 4. Injection of saline on days 2 and 4 did not produce any changes in pain tolerance compared with days 1 and 3 . To ascertain whether naloxone affected the hot-plate test, mice in group 3 (the 'naloxone group', black bars) received similar treatment procedure as group 2, with saline replaced by naloxone. Similarly, naloxone injection produced no change in pain tolerance, either. This indicates that saline injection or naloxone per se does not affect this type of experimental pain.

$F(9,99)=19.01 ; \quad P<0.0001)$. The mean paw latency after saline injection on day 1 at 8:30 a.m. and day 2 at 8:30 p.m. was $17.26 \pm 1.06 \mathrm{~s}$ and $17.22 \pm 1.30 \mathrm{~s}$, respectively. When morphine was administered on day 1 at 8:00 p.m. and day 2 at
8:00 a.m., a significant increase in pain tolerance was found $(34.41 \pm 3.32 \mathrm{~s}$ and $35.02 \pm 3.98 \mathrm{~s}$, respectively, NewmanKeuls' test, $P<0.01)$. Similar results were obtained on days 3 and 4 (Newman-Keuls' test; $P<0.01$ ). After saline treatment on day 5 at 8:00 a.m. and a 30-min exposure to the cue compartment in group 4 rats, pain tolerance was significantly elevated compared with both day 1 at 8:30 a.m. in group 4 $(26.81 \pm 3.45 \mathrm{~s}$ vs17.26 $\pm 1.06 \mathrm{~s}$, Newman-Keuls' test, $P<0.01)$ and day 5 at 8:30 a.m. in group 1 (natural history, $16.81 \pm 1.57 \mathrm{~s}$, $t$-test, $P<0.01$ ), indicating that the previous morphine conditioning was sufficient to evoke a placebo effect. However, if naloxone was administered on day 5 at 8:00 a.m. (group 5), pain response latency was not increased compared with either day 1 at 8:30 a.m. in the same group $(17.73 \pm 2.08 \mathrm{~s}$ vs $17.26 \pm 1.06 \mathrm{~s}$, NewmanKeuls' test, $P>0.05$ ), or day 5 at 8:30 a.m. in group 1 (natural history, $16.81 \pm 1.57 \mathrm{~s}, t$-test, $P>0.05$ ). A significant difference was also observed between groups 4 and 5 at day 5 at 8:30 a.m. $(26.81 \pm 3.45 \mathrm{~s}$ vs $17.73 \pm 2.08 \mathrm{~s}$, $t$-test, $P<0.01)$. Therefore, the morphine conditioning-induced placebo effect was completely blocked by naloxone. Without exposure to the cue compartment, the pain tolerances in both groups were restored to the control level on day 5 at 8:30 p.m. $(17.13 \pm 1.38 \mathrm{~s}$ and $17.02 \pm 1.33 \mathrm{~s}$, respectively, Newman-Keuls' test, $P>0.05$ ) (See Figure 4).

\section{Effect of conditioned cue with aspirin conditioning}

The same procedures described earlier were repeated with the non-opioid aspirin. A significant difference was shown in group 6 when the paw latency was measured for five consecutive days (ANOVA, $F(9,99)=6.89 ; P<0.0001$ ). The mean paw latency at 8:30 a.m. on day 1 and 8:30 p.m. on day 2 was $17.78 \pm 1.45 \mathrm{~s}$ and $17.47 \pm 0.98 \mathrm{~s}$, respectively. Administration of aspirin on day 1 at 8:00 p.m. and day 2 at 8:00 a.m.
A

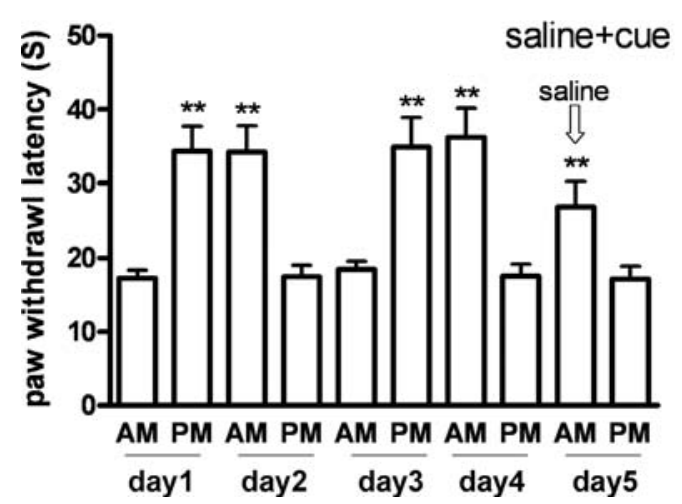

B

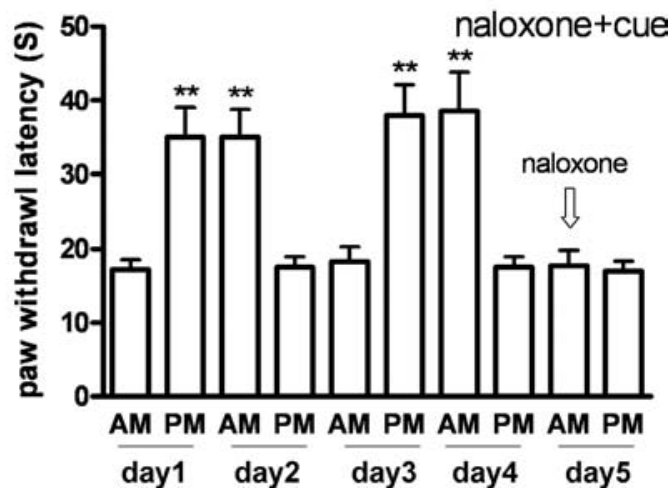

Figure 4 Morphine-induced placebo effect and its modulation with naloxone. (A) After the procedure of morphine conditioning on day 1-4, mice were injected with saline (group 4) and put into the conditioned cue box for 30 min on day 5 at 8:00 a.m.. Paw withdrawal latency was significantly elevated, which mimics the morphine analgesic response. (B) When an injection of naloxone (group 5) was delivered before the exposure to cue environment after morphine conditioning, the morphine-mimicking effect was completely abolished. ${ }^{* *} P<0.01$, compared with day 1 at $8: 30$ a.m. (control condition). 
A

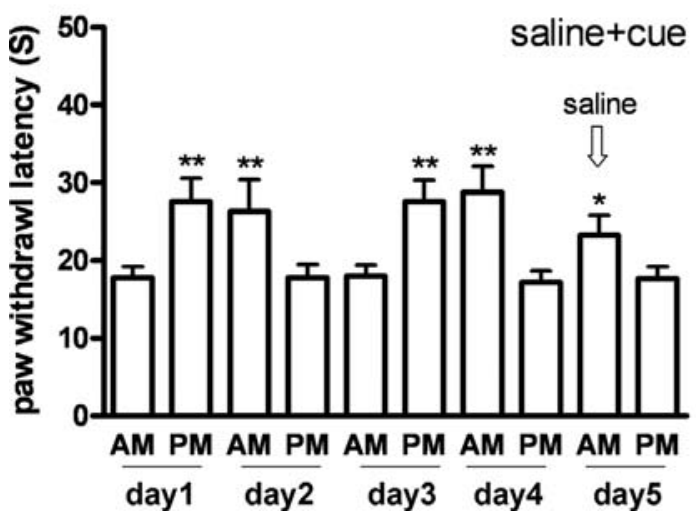

B

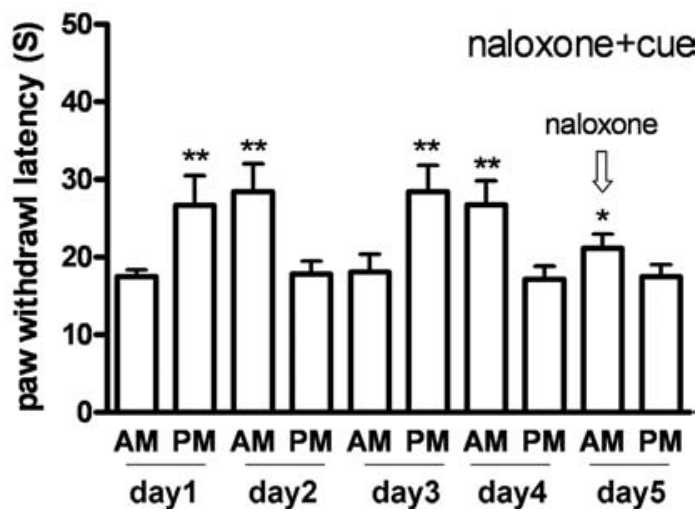

Figure 5 Aspirin-induced placebo effect and its modulation with naloxone. (A) After the procedure of aspirin conditioning on day 1-4, mice received a saline injection (group 6) and stayed in the cue chamber on day 5 at 8:00 a.m. for 30 min. Paw withdrawal latency was significantly increased, which mimics the aspirin analgesic response. (B) When an injection of naloxone (group 7) was employed instead of saline, the placebo effect was not affected. ${ }^{* *} P<0.01,{ }^{*} P<0.05$, compared with day 1 at 8:30 a.m. (control condition).

produced strong analgesic responses $(27.55 \pm 3.06 \mathrm{~s}$ and $26.70 \pm 3.84 \mathrm{~s}$, repsectively, Newman-Keuls' test, $P<0.01$ ). The same results were also acquired on days 3 and 4 (Newman-Keuls' test, $P<0.01$ ). After saline was administered on day 5 at 8:00 a.m., rats in group 6 were put into the cue compartment, and their pain tolerance was significantly elevated compared with both day 1 at 8:30 a.m. of this group $(23.26 \pm 2.54 \mathrm{~s}$ vs $17.78 \pm 1.45 \mathrm{~s}$, Newman-Keuls' test, $P<0.05$ ) and day 5 a.m. in group 1 (natural history, $16.81 \pm 1.57 \mathrm{~s}, t$-test, $P<0.05$ ). However, when naloxone was administered instead of saline in the same procedure on day 5 , the mean paw latency of rats in group 7 remained elevated $(21.17 \pm 1.75 \mathrm{~s})$ above both day 1 at $8: 30$ a.m. in the same group $(17.78 \pm 1.45 \mathrm{~s}$, Newman-Keuls' test, $P<0.05)$ and day 5 a.m. in group 1 (natural history, $16.81 \pm 1.57 \mathrm{~s}, t$-test, $P<0.05$ ). No significant difference was observed between groups 6 and 7 at day 5 at 8:30 a.m. (23.26 $\pm 2.54 \mathrm{~s}$ vs $21.17 \pm 1.75 \mathrm{~s}, t$-test, $P>0.05$ ). Therefore, in this case, the placebo analgesia was still present and the aspirin-conditioned analgesia was not blocked by naloxone. When the rats were not exposed to the cue compartment, the pain tolerances in groups 6 and 7 returned to control level on day 5 at 8:30 p.m. $(17.67 \pm 1.57 \mathrm{~s}$ and $17.48 \pm 1.52 \mathrm{~s}$, respectively, NewmanKeuls' test, $P>0.05$ ) (See Figure 5).

\section{Discussion}

The major findings of the present investigation were as follows: 1) mice can learn to associate the context cue with elevated pain tolerance via a set of procedures. After mice were given four days of drug conditioning with the conditioned cue stimulus (i.e., the chamber) and the unconditioned drug stimulus (morphine or aspirin), saline injection with the contextual cue could produce placebo analgesia at day 5. 2) As placebo response can be subdivided into opioid and non-opioid components in human, it can also be mediated by opioid or nonopioid mechanisms in mice, depending on the analgesics used during the training procedure, namely, morphine conditioning produced a placebo response that was completely antagonised by naloxone. By contrast, aspirin conditioning elicited a placebo effect that was not blocked by naloxone.

Historically, there have been two primary perspectives for approaching the mechanism underlying the placebo effect. Conditioning theorists have proposed that the placebo is a conditioned Pavlovian response, whereas others have advocated that the placebo is driven by expectancy (Wolraich, et al., 1995; Stewart-Williams and Podd, 2004; Haour, 2005; Wager and Nitschke, 2005). Amanzio and Benedetti (1999) addressed that both expectation and conditioning can produce placebo effect. In their experiment, expectation triggered endogenous opioids, whereas conditioning activated specific subsystems. If conditioning was performed with opioids, placebo analgesia was mediated via opioid receptors; if conditioning was performed with nonopioid drugs, other nonopioid mechanisms were involved. So they evoked different types of placebo responses that were either naloxone-reversible or partially naloxone-reversible, or otherwise, naloxone-insensitive, depending on the procedures used to evoke the placebo response. These findings show that cognitive factors and conditioning are integrated in different ways in placebo analgesia, and this integration is crucial for the activation of opioid or nonopioid systems.

Experience with active treatments may create conditioned associations between treatment context (e.g., an injection) and endogenous neurophysiological responses. Such conditioned responses may be unconscious and involuntary, engaging 
separate neural mechanisms from those involved in expectancy. However, conditioning procedures also create expectations that, in turn, may play a key role in the conditioned response (Kirsch, 1985; Wager and Nitschke, 2005). In our experiment, pain tolerance was measured by hot-plate test, which involved a supraspinally mediated nociceptive response. Mice would lick their hind paws, shake or jump off from the hot surface when they feel pain. After an injection of morphine or aspirin in mice, their pain tolerance was higher than normal condition. With four days of drug conditioning procedure, mice could learn to associate the conditioned cue with analgesia. Thus, when mice again received an injection and stayed in the cue chamber on day 5, an endogenous analgesic mechanism might be activated by this procedure. As these drugconditioning procedures might also create expectations, whether the analgesia was related to expectations or conditioning remains unknown. Some theorists proposed that experimental and clinical literature on placebos can be explained in terms of expectations, including the extensive nonhuman animal research using conditioning paradigms to examine the placebo effect. On their opinion, expectation is implicit in conditioned stimuli. The relative contributions of conditioning and expectancy to placebos are difficult to disentangle (Haour, 2005; Klinger, et al., 2007). We currently know very little about the brain processes and pathways involved in expectancy and how they interact with pathways crucial for conditioning. Whether the analgesia was related to expectations or conditioning will be tested by future experiments.

In the current study, morphine hydrochloride was administered at a dose of $10 \mathrm{mg} / \mathrm{kg}$ and at least $12 \mathrm{~h}$ apart from the previous injection. According to Hipps, et al. (1976), morphine levels in brain reached its peak at $30 \mathrm{~min}$ after the subcutaneous injection of $10 \mathrm{mg} / \mathrm{kg}$ of morphine sulfate and then declined rapidly over the next $3 \mathrm{~h}$. Marinho, et al. (2006) showed that morphine produced its maximum antinociceptive effect between 80 and $100 \mathrm{~min}$, and the antinociceptive action of morphine lasted about $140 \mathrm{~min}$. Here at day 5, the nociceptive threshold was measured more than $12 \mathrm{~h}$ after the previous morphine injection. So, it is barely possible that this effect was due to the long-lasting effect of morphine. With the hot-plate assay, Grognet, et al. (1983) reported that $\mathrm{ED}_{50}$ values for morphine varied among strains, being $6.8 \mathrm{mg} / \mathrm{kg}$ for $\mathrm{OF} 1$, $16.9 \mathrm{mg} / \mathrm{kg}$ for CD1, and about $29 \mathrm{mg} / \mathrm{kg}$ for NMRI mice. The dose-response curve of morphine on ICR mice were also measured in our lab, with an $\mathrm{ED}_{50}$ of $12.3 \mathrm{mg} / \mathrm{kg}$. The present morphine dose employed in this study was approximately around a $40 \%$ level. Thus, we consider it as a proper dose for the current procedure.

A problem in Amanzio and Benedetti's experiment was that they could not preclude a previous conditioning in their experimental subjects. In fact, most of the subjects had a previous experience with either opioids or nonopioids (e.g., headache or surgery). Here our mice had never been exposed to either opioids or nonopioids, so the results should be more convincing for a placebo response.
It is important to understand whether the current conditioning was cue- or context-related, because they are thought to be mediated by different brain circuit (Phillips and LeDoux, 1992; Maren, 2008). However, according to the present experimental design, it is difficult to decide which part of the cue chamber was perceived as the conditioned stimulus. Because all the sensory cues related with the box were presented together, they might work as an integrated environmental cue to be associated with the concurrent drug effect. The questions as to which part of the environment served as the cue and what were the neural substrates of the observed placebo analgesia were not the aim of the current study. Thus, these questions will be addressed in our future studies with more strict conditioning control, such as a group with a conditioned stimulus that is not specifically paired with any drug, or a pseudoconditioning group in which the temporal aspects of the pairing are disrupted.

Morphine is the prototype narcotic drug and interacts predominantly with the $\mu$-opioid receptor. Activation of the $\mu$ receptor is associated with analgesia, sedation, euphoria, physical dependence and respiratory depression. Aspirin, on the other hand, has analgesic, anti-inflammatory and antipyretic effects. Any of these effects may serve as the UCS in a conditioning paradigm. However, in the current experimental setting, only the analgesic effect of these drugs was accessed by hot-plate test after training. Thus, we can only be sure that analgesia has become the UCS in our mice. Whether other effects were also successfully conditioned with the CS will need more detailed testing in the future study.

In summary, we demonstrated that if the mice were conditioned with morphine, the placebo analgesia would occur via the opioidergic pathway. If the mice were conditioned with aspirin, the placebo analgesia would occur via some nonopioidergic pathways. It is known that the NSAIDs like aspirin could act at both peripheral and central sites in the spinal cord and inhibit the cyclooxygenase, the enzyme that catalyzes the synthesis of cyclic endoperoxides from arachidonic acid to yield prostaglandins (Simon, 1996; Ellrich, et al., 1999). Thus, the aspirin-conditioned analgesia might act on these mechanisms. Since it remains unknown which brain areas are involved in the opioid and nonopioid placebo process and how the activated brain networks differ, further study will be needed.

\section{Acknowledgements}

This study was supported by NNSF grants (30570577 and 30770688), the 100 Talented Plan of the Chinese Academy of Sciences, and the 863 project (2006AA02Z431) of China to LF; a Director starting grant $(111000 \mathrm{C} 131)$ from IPCAS, a projects for Young Scientist from IPCAS (08CX043004), and a NNSF grant (30800301) to GJY; a projects for Young Scientist from IPCAS (07CX051005) and a NNSF grant (30700223) to WJY.

\section{References}

Amanzio, M, Benedetti, F (1999) Neuropharmacological dissection of placebo analgesia: expectation-activated opioid systems versus conditioning-activated specific subsystems. J Neurosci 19: 484 494. 
Benedetti, F (1996) The opposite effects of the opiate antagonist naloxone and the cholecystokinin antagonist proglumide on placebo analgesia. Pain 64: 535-543.

Benedetti, F, Pollo, A, Lopiano, L, Lanotte, M, Vighetti, S, Rainero, I (2003) Conscious expectation and unconscious conditioning in analgesic; motor and hormonal placebo/nocebo responses. J Neurosci 23: 4315-4323.

Bonnycastle, DD, Cook, L, Ipsen, J (1953) The action of some analgesic drugs in intact and chronic spinal rats. Acta Pharmacol Toxicol 9: 332-336.

Chan, SL, Yeung, JH (2006) Polysaccharide peptides from COV-1 strain of Coriolus versicolor induce hyperalgesia via inflammatory mediator release in the mouse. Life Sci 78: 2463-2470.

Ellrich, J, Schepelmann, K, Pawlak, M, Messlinger, K (1999) Acetylsalicylic acid inhibits meningeal nociception in rat. Pain 81: 7-14.

Fanselow, MS, Poulos, AM (2005) The neuroscience of mammalian associative learning. Annu Rev Psychol 56: 207-234.

Fields, HL, Levine, JD (1984) Placebo analgesia: a role for endorphins? Trends Neurosci 7: 271-273.

Fields, HL, Price, DD (1997) Toward a neurobiology of placebo analgesia. In: Harrington, A (ed), The Placebo Effect: An Interdisciplinary Exploration. Cambridge: Harvard University Press. pp. 93-116.

Garcia, R, Vouimba, RM, Baudry, M, Thompson, RF (1999) The amygdala modulates prefrontal cortex activity relative to conditioned fear. Nature 402: 294-296.

Gracely, RH, Dubner, R, Wolskee, PJ, Deeter, WR (1983) Placebo and naloxone can alter post-surgical pain by separate mechanisms. Nature 306: 264-265.

Grevert, P, Albert, LH, Goldstein, A (1983) Partial antagonism of placebo analgesia by naloxone. Pain 16: 129-143.

Grognet, A, Hertz, F, DeFeudis, FV (1983) Comparison of the analgesic actions of THIP and morphine. Gen Pharmacol 14: 585-589.

Haour, F (2005) Mechanisms of the placebo effect and of conditioning. Neuroimmunomodulation 12: 195-200.

Herrnstein, RJ (1962) Placebo effect in the rat. Science 138: 677-678.

Hipps, PP, Eveland, MR, Meyer, ER, Sherman, WR, Cicero, TJ (1976) Mass fragmentography of morphine: relationship between brain levels and analgesic activity. J Pharmacol Exp Ther 196: 642-648.

Hoehn-Saric, R, Masek, BJ (1981) Effects of naloxone on normals and chronically anxious patients. Biol Psychiatry 16: 1041-1050.

Irwin, S, Houde, RW, Bennett, DR, Hendershot, LC, Steevers, MH (1951) The effects of morphine, methadone and meperidine on some reflex responses of spinal animals to nociceptive stimulation. J Pharmacol Exp Ther 101: 132-143.

Kirsch, I (1985) Response expectancy as a determinant of experience and behavior. Am Psychol 40: 1189-1202.
Klinger, R, Soost, S, Flor, H, Worm, M (2007) Classical conditioning and expectancy in placebo hypoalgesia: a randomized controlled study in patients with atopic dermatitis and persons with healthy skin. Pain 128: 31-39.

Le Bars, D, Gozariu, M, Cadden, SW (2001) Animal models of nociception. Pharmacol Rev 53: 597-652.

Levine, JD, Gordon, NC (1984) Influence of the method of drug administration on analgesic response. Nature 312: 755-756.

Levine, JD, Gordon, NC, Fields, HL (1978) The mechanism of placebo analgesia. Lancet 2: 654-657.

Maren, S (2008) Pavlovian fear conditioning as a behavioral assay for hippocampus and amygdala function: cautions and caveats. Eur $\mathbf{J}$ Neurosci 28: 1661-1666.

Marinho, BG, Miranda, LS, Gomes, NM, Matheus, ME, Leitão, SG, Vasconcellos, ML, et al. (2006) Antinociceptive action of (+/-)cis-(6-ethyl-tetrahydropyran-2-yl)-formic acid in mice. Eur J Pharmacol 550: 47-53.

Petrovic, P, Kalso, E, Petersson, KM, Ingvar, M (2002) Placebo and opioid analgesia - imaging a shared neuronal network. Science 295: 1737-1740.

Phillips, RG, LeDoux, JE (1992) Differential contribution of amygdala and hippocampus to cued and contextual fear conditioning. Behav Neurosci 106: 274-285.

Pihl, RO, Altman, J (1971) An experimental analysis of the placebo effect. J Clin Pharmacol New Drugs 11: 91-95.

Scott, DJ, Stohler, CS, Egnatuk, CM, Wang, H, Koeppe, RA, Zubieta, JK (2008) Placebo and nocebo effects are defined by opposite opioid and dopaminergic responses. Arch Gen Psychiatry 65: $220-231$.

Simon, LS (1996) Actions and toxicity of nonsteroidal antiinflammatory drugs. Curr Opin Rheumatol 8: 169-175.

Sinclair, JG, Main, CD, Lo, GF (1988) Spinal vs supraspinal actions of morphine on the rat tail-flick reflex. Pain 33: 357-362.

Stewart-Williams, S, Podd, J (2004) The placebo effect: dissolving the expectancy versus conditioning debate. Psychol Bull 130: 324-340.

Wager, TD, Nitschke, JB (2005) Placebo effects in the brain: linking mental and physiological processes. Brain Behav Immun 19: 281282.

Wager, TD, Scott, DJ, Zubieta, JK (2007) Placebo effects on human mu-opioid activity during pain. Proc Natl Acad Sci USA 104: 11056-11061.

Wolraich, ML, Wilson, DB, White, JW (1995) The effect of sugar on behavior or cognition in children. A meta-analysis. JAMA 274: $1617-1621$.

Zimmermann, M (1983) Ethical guidelines for investigations on experimental pain in conscious animals. Pain 16: 109-110. 